\title{
Academic Reference and Instruction Librarians and Dweck's Theories of Intelligence
}

\author{
Amanda L. Folk
}

This article introduces psychologist Carol S. Dweck's entity and incremental theories of intelligence and explores the prevalence of these theories in academic librarians who participate in reference and instruction activities. Based on existing research, it is possible that implicit theories of intelligence could affect the ways in which librarians conduct information literacy and library instruction, as well as reference interactions. This article intends to provide a foundation for understanding if further research concerning theories of intelligence, instructional design and pedagogy, and reference practice in academic libraries is warranted.

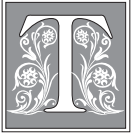

he value that instruction and reference librarians add to a postsecondary education is the development of information-literate graduates who demonstrate sound higher-order thinking skills and the capacity for lifelong learning and intellectual growth. With this value in mind, academic instruction and reference librarians must continually balance teaching students both basic information literacy skills and the higher-order thinking skills required of a truly information-literate individual. Even if students received excellent library and information literacy instruction in their $\mathrm{K}-12$ experience, postsecondary academic work requires a new set of tools with which many of them will be unfamiliar. However, as indicated in the Information Literacy Competency Standards for Higher Education, librarians are tasked with helping students move beyond basic skills to the development of higher-order thinking skills. The revision of Bloom's taxonomy of educational objectives identifies these high-order thinking skills as apply, analyze, evaluate, and create. ${ }^{1}$ Cindy McHenry Rogers notes that these higher-order thinking skills are what help students to "become productive citizens and compete in a global community," which resonates with the Association of College and Research Libraries' (ACRL) goal of promoting lifelong learning through the development of information literacy skills. ${ }^{2}$

However, these higher-order skills do not come naturally to all students; some will need to work with professors and librarians to develop and hone these skills over time. The recently adopted Framework for Information Literacy for Higher Education notes that students who are developing their information literacy skills exhibit particular dispositions or "preferences, attitudes, and intentions." ${ }^{3}$ This acknowledgement suggests librarians are tasked with helping students to develop the dispositions neces-

Amanda L. Folk is Director of Millstein Library and Coordinator of Regional University Library System Libraries at the University of Pittsburgh; e-mail: alfolk@pitt.edu. (C) 2016 Amanda L. Folk, AttributionNonCommercial (http://creativecommons.org/licenses/by-nc/3.0/) CC BY-NC. 
sary to become information-literate adults. Sherry R. Crow writes, "we are not in the business of creating information-finding robots that produce the minimum product for the grade"; rather, "our primary goal is to foster students who are on their way to becoming lifelong learners, 'people who display an attitude and ability that prompts them to learn across their life spans.'" 4 To do this, librarians must value these dispositions and promote them through instruction and reference interactions with students.

Psychologist Carol S. Dweck's research on theories of intelligence could provide some insight regarding how academic librarians can promote and develop the dispositions of an information-literate individual. Dweck's theories of intelligence are based on whether one believes intelligence is fixed (entity theory) or is something that can be developed over time (incremental theory). ${ }^{5}$ While Dweck's theories of intelligences have been primarily applied to $\mathrm{K}-12$ education settings, it is possible that implicit theories of intelligence could affect the ways in which librarians conduct information literacy and library instruction, as well as reference interactions. Previous research has indicated a teacher's theory of intelligence could affect instructional goals, perceptions of student ability, and help-seeking behavior in students, as well as a teacher's desire to improve his or her teaching skills. ${ }^{6}$

The purpose of this article is to introduce Dweck's theories of intelligence and to provide a foundation for understanding if further research concerning theories of intelligence, instructional design, and reference practice in academic libraries is warranted. The following questions will be used to explore the prevalence of these theories of intelligence in a group of self-selected academic librarians who participate in reference and instruction activities:

- Do academic librarians who participate in reference and instruction tend to subscribe to one implicit theory of intelligence more than the other?

- Do academic librarians who participate in reference and instruction tend to subscribe to one theory of student intelligence more than the other?

- Do academic librarians who participate in reference and instruction hold the same theories of intelligence when applied to themselves, as well as to students?

- Are various background characteristics of academic librarians who participate in reference and instruction, such as institution type or years of experience, related to the subscription to a particular theory of intelligence?

Dweck's theories of intelligence have not yet been investigated in terms of academic libraries, so the empirical portion of this article is exploratory in nature. Exploratory studies are used to determine if future research on a topic is warranted and to provide a foundation for developing additional research questions and study designs. Earl Babbie writes that "exploratory studies are quite valuable in social science research," especially "whenever a researcher is breaking new ground."7 However, exploratory studies only "hint at the answers" regarding a phenomenon and its prevalence in a representative sample of a population, rather than providing a complete picture. ${ }^{8}$

\section{Theoretical Framework}

Dweck's entity and incremental theories of intelligence will be used to investigate the beliefs that a self-selected sample of academic librarians who participate in reference and instruction activities have regarding the ability to change or develop intelligence. According to this framework, librarians who subscribe to an entity theory of intelligence, which is sometimes referred to as a fixed mindset, believe intelligence is a trait with which one is born and is something that cannot be changed. On the other hand, librarians who subscribe to an incremental theory of intelligence, also known as a growth mindset, believe intelligence is a trait that can be developed as one learns. Mara Houdyshell, Yi Hua, and Patricia A. Robles surveyed more than 500 hundred librarians 
and found that 82 percent indicated they chose librarianship as a career because of the intellectual challenge. ${ }^{9}$ This suggests that a career in librarianship might appeal more to those who hold an incremental theory of intelligence.

Dweck and her colleagues argue that theories of intelligence often manifest when a person is confronted with a challenging task or the potential for failure. Based on one's reaction to these situations, Dweck finds that a person will exhibit either helpless or mastery-oriented pattern. When entity theorists face challenging tasks, they are quick to "denigrate their abilities," even if they had experienced success prior to confronting the potential for failure. ${ }^{10}$ Entity theorists are quick to give up, because they believe that putting effort into a task is an indictment of their intelligence. In other words, they believe that if they had the intellectual ability to complete the task, they would not need to exert effort. Not only do entity theorists tend to give up quickly, Dweck's research shows they are also less likely to solve easier problems, ones that they had already successfully solved, after being confronted with a challenge. Dweck writes that the helpless pattern "is a reaction to failure that carries negative implications for the self and that impairs students' ability to use their minds effectively." ${ }^{\prime 11}$

Conversely, when incremental theorists face challenging tasks, they exhibit masteryoriented patterns. Dweck reports that incremental theorists begin "issuing instructions to themselves on how they could improve their performance" and dig in "more vigorously." 12 Incremental theorists do not worry about failure when confronted with a challenge, because they believe putting effort into a task is not an indictment of ability or intelligence; rather, they believe learning and intellectual growth come from the effort they exert. Based on my reading of several of the dispositions listed under the threshold concepts in the Framework for Information Literacy for Higher Education, students who are developing their information literacy skills exhibit the mastery-oriented response common to incremental theorists.

A person's theory of intelligence not only influences the way a person judges his or her own intellectual ability, but also how a person judges others' intellectual abilities. In general, entity theorists are more likely to chalk up achievement to intellect and natural ability, whereas incremental theorists are more likely to recognize that hard work, preparation, and strategy are important for achievement. ${ }^{13}$ Furthermore, Dweck notes that entity theorists believe the quick global trait judgments they make come from "reading others' traits from reliable information." ${ }^{14}$ While quick judgments can be beneficial in some cases, research has found that "entity theorists, once they have formed an impression, are often less sensitive to new, contradictory information... and may even try to avoid it." ${ }^{15}$ Dweck writes that "entity theorists saw behaviors more readily as reflecting the underlying traits of a group," meaning that their judgments are applied to both individuals and groups. ${ }^{16}$ First impressions could have implications for how teachers, including librarians, develop relationships and deliver instruction to students.

Ultimately, neither theory is better than the other, and "it has not been demonstrated that implicit theories rigidly determine people's behavior." 17 Instead, Rogers writes that "Dweck and her colleagues view these theories simply as alternative ways of constructing reality, each with is [sic] potential costs and benefits." ${ }^{18}$ However, Dweck does outline some potential implications for educators to bear in mind. Students who are entity theorists, particularly those who are underachieving, could benefit from being encouraged to take on a mastery-oriented response to challenging work. Underachievement does not have to be an indictment of a student's potential to succeed. However, educators who rely on initial judgments of intelligence and potential might be more likely to "relegate them [underachieving students]...to a lower level of intelligence, assign them easier things to learn, and try to make them feel smart learning the easier 
things - to protect their self-esteem."19 Since students develop higher-order thinking skills, including problem-solving and critical-thinking skills, through the development of information literacy skills, this latter approach seems to be antithetical to the kind of pedagogy required to develop information-literate students.

\section{Theories of Intelligence and the Teacher}

Rick VanDeWeghe presents a scenario that many college instructors and librarians would understand - some students' (including bright and competent students) hesitation and discomfort when presented with a research assignment. ${ }^{20} \mathrm{He}$ uses this scenario to frame a discussion of how students' theories of intelligence manifest in the college classroom and outlines practices that college instructors can employ to combat helplessness or to encourage a mastery-oriented goal. The practices that VanDeWeghe discusses, which are based on Dweck's research, will be addressed in the discussion section.

In an interview with Educational Horizons, Dweck discusses the importance of the incremental theory to teaching. While her remarks primarily focus on teaching children, there are some important takeaways for developing the types of dispositions mentioned above. Dweck's research has shown that theories of intelligence can be learned through appropriate criticism and praise, as well as mentoring. ${ }^{21}$ Furthermore, a teacher's theory of intelligence could impact his or her students' achievement or academic growth. Finally, an entity theory could limit the teacher's ability to grow and develop as a professional. Despite this, research on theories of intelligence has primarily focused on the individual student rather than on teachers. However, several studies investigating the effects of a teacher's theory of intelligence and the classroom have been conducted. The results of these studies have been inconsistent but are still worth investigating further.

A teacher's theory of personal intelligence could affect his or her own professional development and growth. Jennifer McCrickerd combines Dweck's theories of intelligence with Fisher's dynamic skill theory to understand why college faculty might not be willing to change their teaching methods and take risks in the classroom. ${ }^{22}$ Based on existing research, McCrickerd hypothesizes that many faculty members subscribe to an entity theory of intelligence. Improving teaching requires taking risks, and, in addition to lack of institutional incentives, many faculty might fear failure when trying new techniques. McCrickerd believes that institutions should provide development opportunities that discourage this kind of thinking and "encourage risk taking." 23 Librarians engaging in reference and instruction activities who subscribe to an entity theory of intelligence might resist development opportunities for these same reasonsrisk of failure and lack of encourage for innovation.

Sungok Serence Shim, YoonJung Cho, and Jerrell Cassady investigated the relationship between teachers' theories of student intelligence, achievement goals for teaching, and classroom goal structures. The authors hypothesized that teachers subscribing to an incremental theory of student intelligence would be more likely to set masteryoriented achievement goals for their classrooms, and "the effect of implicit theories of intelligence on classroom goal structures would be mediated by achievement goals for teaching." ${ }^{24}$ While both types of classroom goals have positive aspects, research has indicated performance-oriented goals can create "a more competitive environment... where value is placed on demonstrating superior ability and outperforming others." 25 Interestingly, the authors did not find that teachers' theories of student intelligence had an effect on classroom goal structures. However, achievement goals for teaching were strongly related to classroom goal structure. Since this study did not account for teachers' theories of personal intelligence, it is unknown if theories of personal intelligence affect a teacher's achievement goals for teaching, which could ultimately influence his or her classroom goal structure. 
A classroom's goal structure could have a real effect on whether or not students seek help with their academic work. Allison M. Ryan, Margaret H. Gheen, and Carol Midgley hypothesize that when students believe their teacher emphasizes a relative-ability goal structure, which is similar to a performance-oriented goal structure, students will be less likely to ask for help. On the other hand, if students believe their teacher emphasizes a task-focused goal structure, which is similar to a mastery-oriented goal structure, then "students should be more inclined to ask questions to gain mastery." 26 The findings of this study confirmed this hypothesis, although the overall picture is more complex. The authors found that individual characteristics, such as academic self-efficacy and gender, also factored into a student's decision to seek help. Overall, the authors also found students' beliefs about the classroom goal structure predicted helpseeking behavior, but teachers' beliefs about their classrooms' goal structures did not.

Rogers wanted to know if teachers' theories of intelligence affected whether or not they believed that low-achieving students could or should be taught higher-order thinking skills. Rogers found that "teachers who held an entity view of intelligence were less likely than teachers who held an incremental view of intelligence to teach higher-order thinking skills to students who were identified as low-achieving." ${ }^{27}$ This difference, however, was not found with respect to the teaching of higher-order thinking skills to high-achieving students. In a different study, Ruth Butler found that teachers who are entity theorists might "perceive initial achievement as diagnostic of pupil ability" and could "under- or overestimate later outcomes to conform with their initial judgment." ${ }^{28}$ These findings suggest that a teacher's implicit theory of intelligence could significantly affect the skills he or she believes should be taught to the segment of the student population most at risk for failure and could result in a lack of engagement on the part of low-achieving students.

\section{Methodology}

After receiving approval from the University of Pittsburgh's Institutional Review Board, a call for participation was distributed using relevant listservs (collib-1, ili-1, brass-1, rusa-1, rss-1, and infolit-1), Facebook groups (ALA Think Tank), and the author's personal Facebook page. Prior to distributing the survey, the author received feedback from professional colleagues regarding the survey questions. Since the questions related to theories of intelligence were taken or adapted from Dweck's previous research, the author was interested in validating the demographic questions and changed some of the wording based on the feedback received.

The survey, which was created in Qualtrics, took about five to seven minutes to complete and consisted of ten demographic questions and eleven statements regarding theories of intelligence. In a few cases, the branching feature was used to elicit more information depending on how a participant responded to the previous question. For example, if a participant indicated that neither reference nor instruction were part of his or her primary job responsibilities, he or she was asked to estimate the number of hours per week he or she spends on reference and instruction activities.

As mentioned, all of the statements regarding theories of intelligence were taken or adapted from Dweck. ${ }^{29}$ Reliability and validity data regarding the original statements can be found in previously published research. ${ }^{30}$ The first set of statements regarding the nature of human intelligence intended to gauge how the participant understood his or her own intelligence. For instance, statements included "You [emphasis added] have a certain amount of intelligence, and you can't really do much to change it" and "You can always substantially change how intelligent you are." The wording of the six statements included in this section is taken directly from Dweck and has not been altered. The second set of statements regarding the nature of human intelligence were intended to gauge how the participant felt about the nature of students' intelligence. 
Statements used in the first section were adapted to reflect this. Examples include "Students [emphasis added] have a certain amount of intelligence, and they can't really do much to change it" and "Students can always substantially change how intelligent they are." There were five questions related to the nature of students' intelligence in total. Reliability data for these questions will be discussed in the results section. For both sets of statements, participants were asked to select from strongly agree, agree, disagree, and strongly disagree. Providing these four options meant participants would not have the ability to take a neutral stance on any of the statements.

Demographic questions that might induce stereotype threat in the participants, such as gender or years of experience, were asked at the end of the survey. The question regarding gender was open ended to recognize that not all of the participants would feel comfortable choosing between male or female.

\section{Participants}

While the survey was accessible to anyone, the intended primary audience was academic librarians engaged in reference and instruction activities working in the United States, which is reflected in the distribution channels used. The survey's introduction stated, "Any librarian who performs instruction or reference work in an academic library is invited to participate." Of the 353 participants who started the survey, 259 completed the survey in full, 291 participants completed the survey through the first set of statements (those regarding the nature of one's own intelligence), and 279 participants fully responded to both sets of statements regarding intelligence. Responses from the 279 participants who fully responded to both sets of questions were used for analysis.

The survey asked a number of demographic questions in an effort to understand the composition of the sample. Table 1 provides demographic information for the participants. The majority of participants $(78 \%)$ reported that both reference and instruction were part of their primary job responsibilities. More than 70 percent of the participants reported that they had been in the library profession for 10 years or less (mean=10.73 years), with almost 60 percent serving in their current positions for 5 years or less (mean $=5.91$ years). Almost 40 percent of participants reported working at a research university, and fully 24 percent reported working at a master's institution. The majority of participants (55\%) reported that they primarily work with undergraduates, although fully 38 percent reported that they work with both undergraduate and graduate students. An overwhelming majority of participants (85\%) identified as female.

\section{Limitations}

It should be noted there are limitations to this study, as well as to the interpretation of the results. The sample used in this study is self-selected and one of convenience and does not reflect the larger population of academic librarians who engage in reference or instruction activities. Because of this, any inferences or predictions about this larger population and theories of self or student intelligence are unwarranted. In other words, the findings of this study are limited to the participants only. The survey distribution methods could have affected the survey responses, in that the survey was primarily advertised on online professional resources like listservs and Facebook pages. It is impossible to say if the participants are different from those who chose not to respond. It is also impossible to say if the participants are different from librarians who do not regularly check these online professional resources.

In addition, certain subgroups might be overrepresented in this study, such as librarians with less than 10 years of experience or librarians who identify as female. This potential overrepresentation could affect the outcome of the chi-squared tests, which attempted to identify any relationships between background characteristics and theories 


\begin{tabular}{|c|c|c|c|}
\hline \multicolumn{4}{|c|}{$\begin{array}{c}\text { TABLE } 1 \\
\text { Participants' Demographic Information }\end{array}$} \\
\hline & $\mathrm{n}(\%)$ & & $\mathrm{n}(\%)$ \\
\hline \multicolumn{2}{|c|}{ Primary job duties $(\mathrm{N}=279)$} & \multicolumn{2}{|c|}{ Years in current position $(\mathrm{N}=275)$} \\
\hline Reference & $11(3.94)$ & Less than 1 year & $19(6.91)$ \\
\hline Instruction & $21(7.53)$ & $1-5$ years & $145(52.73)$ \\
\hline Reference and instruction & $219(78.49)$ & $6-10$ years & $65(23.64)$ \\
\hline \multirow[t]{4}{*}{ Other } & $28(10.04)$ & $11-15$ years & $22(8.00)$ \\
\hline & & $16-20$ years & $16(5.82)$ \\
\hline & & 21 or more years & $8(2.91)$ \\
\hline & & \multicolumn{2}{|c|}{ Institution's Carnegie classification $(\mathrm{N}=279)$} \\
\hline \multicolumn{2}{|l|}{ Gender $(\mathrm{N}=274)$} & Associate's_Public & $40(14.34)$ \\
\hline Male & $39(14.23)$ & Associate's-Private & $1(0.36)$ \\
\hline Female & $233(85.04)$ & Baccalaureate College & $45(16.13)$ \\
\hline Cisgender & $1(0.36)$ & Master's & $69(24.73)$ \\
\hline \multirow[t]{4}{*}{ Transgender } & $1(0.36)$ & Research University & $106(37.99)$ \\
\hline & & Special Focus Institution & $5(1.79)$ \\
\hline & & Not sure & $5(1.79)$ \\
\hline & & Other & $8(2.87)$ \\
\hline \multicolumn{2}{|c|}{ Years as a professional librarian $(\mathrm{N}=273)$} & \multicolumn{2}{|c|}{ Primary student audience $(\mathrm{N}=278)$} \\
\hline Less than 1 year & $5(1.83)$ & Undergraduates & $154(55.40)$ \\
\hline $1-5$ years & $98(35.90)$ & Graduates & $16(5.76)$ \\
\hline $6-10$ years & $96(35.16)$ & Both & $107(38.49)$ \\
\hline $11-15$ years & $6(2.20)$ & Other & $1(0.36)$ \\
\hline $16-20$ years & $29(10.62)$ & & \\
\hline $21-25$ years & $18(6.59)$ & & \\
\hline 26 or more years & $21(7.69)$ & & \\
\hline
\end{tabular}

of intelligence in this sample that could warrant further exploration. Furthermore, the findings are based on voluntary, self-reported information, which may not be entirely accurate. Finally, this study cannot determine if and how theories of intelligence affect practice, so any statements made in the following sections regarding the potential intersections of theories of intelligence and practice are strictly speculative and based on the literature reviewed in this article.

\section{Results}

Prior to analysis, Cronbach's alpha was computed using Stata to determine the internal-consistency reliability for the statements regarding the nature of one's own intelligence (self theory) and the nature of students' intelligence (student theory), as well as all of the statements together (overall theory). Cronbach's alpha was 0.83 for the six self-theory statements and 0.91 for the five student-theory statements. For all 


\begin{tabular}{|c|c|c|c|}
\hline \multicolumn{4}{|c|}{$\begin{array}{c}\text { TABLE } 2 \\
\text { Distribution of Theories of Intelligence }\end{array}$} \\
\hline & $\operatorname{Self}(N=279)$ & Student $(N=279)$ & Overall $(N=279)$ \\
\hline Theory & $\mathrm{n}(\%)$ & $\mathrm{n}(\%)$ & $\mathrm{n}(\%)$ \\
\hline Entity & $68(24.37)$ & $91(32.62)$ & $88(31.54)$ \\
\hline Incremental & $183(65.59)$ & $188(67.38)$ & $191(68.46)$ \\
\hline Neutral & $28(10.04)$ & $0(0.00)$ & $0(0.00)$ \\
\hline Strong entity & $16(5.73)$ & $47(16.85)$ & $15(5.38)$ \\
\hline Strong incremental & $121(43.37)$ & $137(49.10)$ & $113(40.50)$ \\
\hline Mean score & 2.80 & 2.75 & 2.77 \\
\hline \multicolumn{4}{|c|}{$\begin{array}{l}\text { Note: Entity theorists had a mean score below } 2.5 \text {. Incremental theorists had a mean score above } 2.5 \text {. } \\
\text { Neutral participants had a mean score that equaled } 2.5 \text {. Strong entity theorists had a mean score equal } \\
\text { to or below } 2 \text {, and strong incremental theorists had a mean score equal to or above } 3 \text {. }\end{array}$} \\
\hline
\end{tabular}

11 statements together, Cronbach's alpha was 0.93. In general, Cronbach's alpha values above 0.70 are considered to be reasonably reliable. Based on these Cronbach's alpha values, the responses to these statements can be considered reasonably reliable.

Table 2 provides the distribution of entity and incremental theorists regarding both self and student theories, as well as the distribution of theorists when the mean scores of all eleven statements were taken into account. For the sake of comparison, Dweck reports that participants, particularly students, are typically divided in half regarding helpless (entity) and mastery-oriented (incremental) responses, with roughly 15 percent "who don't really fit into either group." 31 In this study, the mean score for all participants regarding the self-theory statements was 2.80 , and the mean score regarding student-theory statements was 2.75 . The majority of participants $(65 \%-67 \%)$ had a mean score above 2.5 for theories of intelligence regarding both the self and student, meaning they exhibit an incremental theory of intelligence. Fully 10 percent of participants had a mean score that was exactly 2.5 and were categorized as neutral regarding the self theory, although no participants were neutral regarding the student theory.

Interestingly, more participants exhibited an entity theory of intelligence regarding student intelligence than regarding the self. Since the difference between the number of entity theorists regarding self and students was almost exactly the same as the number of neutral theorists regarding the self, I investigated the mean scores for theories of student intelligence for this group of neutral self theorists. Of the 28 neutral self theorists, twenty (71\%) exhibited an entity theory regarding students. This number accounts almost, but not quite, entirely for the difference in the number between entity theorists regarding self and student theories of intelligence. Only two of these neutral theorists were classified as strong entity theorists regarding student intelligence; most were moderate entity theorists (see next paragraph).

The categories of entity and incremental theorists were broken down even further to determine how many "strong" theorists existed in each of the two categories. As indicated in table 2, the majority of incremental theorists regarding both self and student theories of intelligence are strong incremental theorists, meaning that their mean scores are 3 or higher. Of those who were categorized as incremental theorists, 66 percent were strong incremental theorists regarding the self and almost 73 percent were strong incremental theorists regarding students. An unexpected finding is the difference in the 
number of strong entity theorists between self and student theories of intelligence. Only 16 participants had a mean score of 2 or lower regarding the statements related to the self, thus categorizing them as strong entity theorists. However, 47 participants were categorized as strong entity theorists regarding student intelligence. Interestingly, 39, or 83 percent, of these 47 who hold a strong entity theory of student intelligence had a mean score of 2, which puts them right on the margin of being strong entity theorists. Only 8 of these 47 had mean scores that were below 2. A similar, yet weaker, pattern is observed regarding strong incremental theorists of student intelligence, with 83, or 61 percent, of the strong incremental theorists of student intelligence having a score that places them on the cusp of this category. In general, it appears that participants' theories of intelligence, including both entity and incremental theories, are much stronger regarding students than regarding the self.

A chi-squared test was performed after creating two new variables for scales of self and student theories of intelligence-strong entity, weak entity, neutral, weak incremental, and strong incremental. The chi-squared test indicated there is a statistically significant $(p<0.05)$ relationship between these two scales. In other words, there is a significant relationship in holding the same theory of intelligence for both self and students.

Other chi-squared tests were performed to determine if a statistically significant relationship existed between the theories of both self and student intelligence and participants' background characteristics, including institutional characteristics. Crosstabulations and chi-squared tests were first performed for both the self and student theories and participants' background information, including the librarian's primary job responsibilities, gender, the number of years he or she has been a librarian, and the number of years he or she has served in the respective current position. These cross-tabulations and chi-squared tests revealed that a statistically significant relationship does not exist $(p>0.05)$ between either theory of intelligence, self or student, and participants' background characteristics. Cross-tabulations and chi-squared tests were then performed for both theories of intelligence and institutional characteristics, including basic Carnegie classification and the type of student with which the librarian primarily works. This analysis also revealed that no statistically significant relationship existed between these variables. While the participants in this study are more likely to be incremental theorists, their background and institutional characteristics do not seem to be associated with their theories of self and student intelligence.

\section{Theories of Intelligence and Practice}

One goal of this article is to introduce Dweck's theories of intelligence, as it has not yet been explored within the academic library literature. Based in the existing literature, this section will explore how Dweck's theories of intelligence might influence reference and instruction librarians' interactions with students, as well as how librarians develop as educators.

Whether a librarian is an incremental or entity theorist, there are strategies he or she can employ in both formal and informal teaching opportunities to help students become more comfortable with a mastery orientation. First is the recognition that the current American K-12 educational system might encourage students to think more in terms of performance than mastery due to the enactment of No Child Left Behind and the importance of performance on high-stakes standardized testing. A relatively recent blog post on the Chronicle of Higher Education's website notes that many law school professors report that for some of their students "the challenge of learning on their own is so overwhelming" and that they are "more blatant about just wanting 'the answers.'" 32 Regardless of the K-12 educational environment, some students are simply entity theorists by nature. These students might become frustrated in the classroom or 
during a reference consultation if they feel like they are struggling with certain skills associated with information literacy. This means that the dispositions we are interested in cultivating in our students might not come naturally to all. The onus is on us as educators to find a way to help students to realize that effort does not mean a deficit in ability.

Entity theorists are typically judgmental of their own abilities and performance. However, they are also more likely to attach both positive and negative labels on others, sometimes based on a single good or poor performance. ${ }^{33}$ They are also more likely to attribute a good performance to intellectual ability, rather than acknowledging that hard work and effort might be necessary to achieve or grow intellectually. A reference and instruction librarian who subscribes to an entity theory might be more likely to make a snap judgment about a student's ability or a class's potential based on a single interaction, which could affect the skills the librarian decides to teach or the learning outcomes that a librarian sets for an instruction session. Critical reflection on reference interactions or instruction sessions is one way that all librarians can appreciate how our own theories of intelligence might manifest in our practice as professionals. While some librarians might be hesitant to teach the higher-order teaching skills associated with information literacy to students who have been labeled or perceived as low-performing or underachieving, the challenge might engage these students more than a review of or remediation in basic skills would.

In addition to reflexive practice, both Dweck and VanDeWeghe discuss the importance of praise and criticism in developing mastery-oriented students. Both authors stress that it is important that we praise effort over performance and criticize process, not performance. Dweck writes, "It has become common practice in much of our society to praise students for their performance on easy tasks, to tell them they are smart when they do something quickly and perfectly. When we do this we are not teaching them to welcome challenge and learn from errors. We are teaching them that easy success means they are intelligent and, by implication, that errors and effort mean they are not." ${ }^{34}$ Even when we think we are bolstering a student's self-confidence through this type of praise, it has the ability to incite maladaptive behavior. Dweck argues that it is important for educators to give students "process praise" or "process feedback," both of which are "oriented to strategy." 35 This type of praise helps a student learn from mistakes or to think about ways that performance could be improved without implying that a student lacks the intelligence or ability to be successful. By focusing on the process, we are helping the student to see that, with a bit of work, he or she has the potential to be successful and that both challenge and failure can be positive in terms of learning. When we are working with students, it is important that we remain cognizant of the feedback we are giving to them, whether it is positive or negative.

Furthermore, reference interactions or instruction sessions offer librarians opportunities to remind students that the research process is not always easy. Telling students that it is normal to experience feelings of frustration when researching a new topic or using a new set of tools reassures them that these feelings are not indicative of their potential for success. Some of us might be able to recall occasions in which students candidly admitted that they felt stupid that they had questions, for not understanding how to use a tool, or for not understanding an argument in a scholarly article. If that student is an entity theorist, he or she might not be able to push past those feeling of inadequacy to develop higher-order and information literacy skills and ultimately be successful in his or her coursework. Reassuring students that these struggles or feelings of inadequacy are completely normal and sharing stories of when you might have had a similar experience might make the research process feel safer in terms of success and failure, as well as helping them to cultivate some of the dispositions critical to information literacy.

Understanding Dweck's theories of intelligence could also aid those who supervise reference staff or coordinate instruction, especially in terms of experimenting with 
new services or learning models, as well as encouraging the pursuit of professional development opportunities. Based on McCrickerd's work, resistance to change or experimentation might manifest based on a person's theory of intelligence. If a librarian believes that failure is an indictment of his or her professional ability, that librarian might be opposed to trying something new. Furthermore, librarians who subscribe to an entity theory might be less likely to engage in professional development opportunities, since they might believe that teaching, whether formal or informal, is an ability rather than a set of skills that can be developed. In light of Dweck's theories of intelligence, supervisors could try to create an environment in which reference and instruction librarians feel safe experimenting with new pedagogical methods or services and encouraged to reflect upon what did or did not work.

\section{Conclusion}

The purpose of this paper was twofold - to introduce Dweck's theories of intelligence and to provide a foundation for understanding if further research concerning theories of intelligence, instructional design, and reference practice in academic libraries is warranted. I argue that further research that is both qualitative and quantitative could benefit our profession. Although a study that explores the prevalence of theories of intelligence in a representative sample could be interesting, I believe that research investigating how theories of intelligence influence practice would be even more valuable. Butler found that some teachers who subscribe to an entity theory of intelligence might not believe in teaching higher-order thinking skills to students who have been labeled as low ability. Some librarians might also make judgments about what should be taught and how based on a perceived level of ability, which could result in student disengagement. As McCrickerd points out, theories of intelligence could determine if or how one develops as a teacher over time. It is possible that incremental theorists are more reflective in their practice and seek opportunities to develop their teaching skills. Understanding if and how these theories of intelligence manifest in librarians' practice could help our colleagues who design and promote professional development opportunities to librarians with teaching responsibilities.

In conclusion, neither theory of intelligence is inherently better than the other. However, a librarian's theory of intelligence could have implications for how he or she interacts with students and contributes to the development of students' information literacy skills. The newly adopted Framework for Information Literacy for Higher Education seems to favor dispositions that are related to the incremental theory and a mastery orientation to information literacy. The incremental theory and mastery orientation might not be natural or comfortable for all students or for all librarians, so thoughtful reflection is necessary to ensure that our practice matches our professional values. Providing our students with thoughtful feedback regarding their information-seeking behavior and information use is one way that we can help them to recognize their potential and to develop the higher-order thinking skills associated with information literacy and the capacity for lifelong learning and intellectual growth.

\section{Acknowledgements}

The author would like to thank Heidi Card, Gretchen Gr Keer, and Micquel Little for their thoughtful feedback in the design and writing stages.

\section{Notes}

1. A Taxonomy for Learning, Teaching, and Assessing: A Revision of Bloom's Taxonomy of Educational Objectives, eds. Lorin W. Anderson and David R. Krathwohl (New York, N.Y.: Longman, 2001). 
2. Cindy McHenry Rogers, "The Relationship between Teachers' Implicit Theories of Intelligence and Their Beliefs about Teaching Higher-Order Thinking Skills to Low-Achieving Students" (EdD diss., California State University, Fresno and University of California, Davis, 2009), 10.

3. Association of College \& Research Libraries, Framework for Information Literacy for Higher Education, Jan. 2015, available online at http://acrl.ala.org/ilstandards/wp-content/uploads/2015/01/ Framework-MW15-Board-Docs.pdf, 4 [accessed 15 February 2015].

4. Sherry R. Crow, "Information Literacy: What's Motivation Got to Do with It?" Knowledge Quest 35, no. 4 (2007): 52.

5. Carol S. Dweck, Self-Theories: Their Role in Motivation, Personality, and Development (Philadelphia, Pa.: Psychology Press, 1999).

6. Sungok Serence Shim, YoonJung Cho, and Jerrell Cassady, "Goal Structures: The Role of Teachers' Achievement Goals and Theories of Intelligence," Journal of Experimental Education 8, no. 1 (2013); Ruth Butler, "Making Judgments about Ability: The Role of Implicit Theories of Ability in Moderating Interference from Temporal and Social Comparison Information," Journal of Personality and Social Psychology 78, no. 5 (2000); Rogers, "The Relationship between Teachers" Implicit Theories of Intelligence"; Allison M. Ryan, Margaret H. Gheen, and Carol Midgley, "Why Do Some Students Avoid Asking for Help? An Examination of the Interplay among Students' Academic Efficacy, Teachers' Social-Emotional Role, and the Classroom Goal Structure," Journal of Educational Psychology 90, no. 3 (1998); Jennifer McCrickerd, "Understanding and Reducing Faculty Reluctance to Improve Teaching," College Teaching 60, no. 2 (2012).

7. Earl Babbie, The Practice of Social Research, 13th ed. (Belmont, Calif.: Wadsworth, Cengage Learning, 2013), 91.

8. Ibid.

9. Mara Houdyshell, Yi Hua, and Patricia A. Robles, "What Were You Thinking? If You Could Choose Librarianship Again, Would You?" Information Outlook 3, no. 7 (1999).

10. Dweck, Self-Theories, 7.

11. Ibid., 9 .

12. Ibid.

13. Gail D. Heyman and Carol S. Dweck, "Children's Thinking about Traits: Implications for Judgments of the Self and Others," Child Development 64, no. 2 (1998); Ying-Yi Hong, "Predicting Trait Versus Process Inference: The Role of Implicit Theories (PhD diss., Columbia University, 1994).

14. Dweck, Self-Theories, 80.

15. Ibid.

16. Ibid., 90.

17. Rogers, "The Relationship between Teachers' Implicit Theories of Intelligence," 22.

18. Ibid.

19. Dweck, Self-Theories, 129.

20. Rich VanDeWeghe, "Students' Views of Intelligence, Teachers' Praise, and Achievement," English Journal 93, no. 2 (2003).

21. Carol Dweck, "Mindsets: How to Motivate Students (and Yourself)," Educational Horizons 91, no. $2(2012 / 2013)$.

22. McCrickerd, "Understanding and Reducing Faculty Reluctance to Improve Teaching."

23. Ibid., 57.

24. Shim, Cho, and Cassady, "Goal Structures," 99.

25. Shim, Cho, and Cassady, "Goal Structures," 85.

26. Ryan, Gheen, and Midgley, "Why Do Some Students Avoid Asking for Help," 529.

27. Rogers, "The Relationship between Teachers' Implicit Theories of Intelligence," 87.

28. Butler, "Making Judgments about Ability," 977.

29. Dweck, Self-Theories, 22, 178.

30. Carol S. Dweck, Chi-yue Chiu, and Ying-yi Hong, "Implicit Theories and Their Role in Judgments and Reactions: A Word from Two Perspectives," Psychological Inquiry 6, no. 4 (1995); Sheri R. Levy, Steven J. Stroessner, and Carol S. Dweck, "Stereotype Formation and Endorsement: The Role of Implicit Theories," Journal of Personality and Social Psychology 74, no. 6 (1998).

31. Dweck, Self-Theories, 7.

32. Michele Goodwin, "Law Professors See the Damage Done by 'No Child Left Behind,'” The Conversation, The Chronicle of Higher Education, March 12, 2013, available online at http://chronicle. com/blogs/conversation/2013/03/12/law-professors-see-the-damage-done-by-no-child-left-behind/ [accessed 15 February 2015].

33. Ibid., 77.

34. Dweck, Self-Theories, 43.

35. Dweck, "Mindsets," 18. 